Article

\title{
Winter Persistent Extreme Cold Events in Xinjiang Region and Their Associations with the Quasi-Biweekly Oscillation of the Polar Front Jet
}

\author{
Jie Jiang and Suxiang Yao * \\ Key Laboratory of Meteorological Disaster of Ministry of Education/Joint International Research Laboratory \\ of Climate and Environment Change/Collaborative Innovation Center on Forecast and Evaluation of \\ Meteorological Disasters, Nanjing University of Information Science and Technology, Nanjing 210044, China; \\ jiejiang_@nuist.edu.cn \\ * Correspondence: yaosx@nuist.edu.cn
}

check for

updates

Citation: Jiang, J.; Yao, S. Winter Persistent Extreme Cold Events in Xinjiang Region and Their

Associations with the Quasi-Biweekly Oscillation of the Polar Front Jet. Atmosphere 2021, 12, 597. https:// doi.org/10.3390/atmos12050597

Academic Editor: Alexander

V. Chernokulsky

Received: 2 April 2021

Accepted: 1 May 2021

Published: 5 May 2021

Publisher's Note: MDPI stays neutral with regard to jurisdictional claims in published maps and institutional affiliations.

Copyright: (C) 2021 by the authors. Licensee MDPI, Basel, Switzerland. This article is an open access article distributed under the terms and conditions of the Creative Commons Attribution (CC BY) license (https:// creativecommons.org/licenses/by/ $4.0 /)$.

\begin{abstract}
Winter persistent extreme cold events (WPECEs) often cause great damage to the development of economies and people's lives. The sub-seasonal variation of the atmospheric circulation is regarded as one of important causes of extreme weather, and is key to propel the extended period prediction. In this paper, we mainly analyze the WPECEs in Xinjiang region and their relationship with the sub-seasonal variation of the East Asian polar front jet (PFJ). The results suggest the persistent extreme cold event (equal or greater than 7 days) occurs most frequently in Xinhe County of Xinjiang region, with obvious inter-annual and inter-decadal variations. Further analysis shows that the variation of the mean temperature in the key area has characteristics of intra-seasonal variation when the WPECE occurs. The result of composite analysis shows that this intra-seasonal variation is related to the sub-seasonal variation of atmospheric circulation, especially the PFJ anomalous activity near Lake Balkhash. By using the power spectrum analysis method, note that the PFJ activity has the characteristics of quasi-biweekly oscillation (QBWO) in WPECEs. On quasi-biweekly scale (10-20-day filtered), the weakening of PFJ, the intensification of the zonal easterly wind in the upper troposphere, the accumulation of the strong cold air, and the intensification of the meridional northerly wind in the lower troposphere enhance the occurrence of WPECEs in Xinjiang. Further investigation indicates that the quasi-biweekly PFJ mainly propagates eastward and southward before the WPECE occurs in Xinjiang, China.
\end{abstract}

Keywords: persistent extreme cold event; polar front jet; quasi-biweekly oscillation

\section{Introduction}

IPCC AR5 indicates that each of the last three decades has been successively warmer at the earth's surface than any preceding decade since 1850, and warming of the climate system is unequivocal. Under the RCP8.5 scenario, the extreme weather and climate events will very likely become more intense and frequent by the end of this century, as global mean surface temperature increases [1]. In many extreme events, extreme low temperature has an important effect on social environment and human life. In recent years, China has suffered frequent persistent extreme cold events in winter. The long durations, wide ranges of influence, and cold-precipitation-freezing disasters [2-4] have a great influence on health, agricultural production, social lives, and other aspects of people's lives [5-8].

The atmospheric low-frequency oscillation generally refers to the 10-100 days of atmospheric oscillation, mainly including 30-60 days intra-seasonal oscillation (ISO) and 10-20 days quasi-biweekly oscillation (QBWO). As early as the 1970s, Madden and Julian $[9,10]$ have found that the tropical atmosphere has a significant 30-60 days ISO in the variation of wind field and surface pressure field. Further studies show that low-frequency oscillation is a global atmospheric variation phenomenon, which exists not only in the 
tropics, but also in the mid-high latitude regions [11-14]. The sub-seasonal variations of atmospheric circulations in the mid-high latitude regions are not only important features of atmospheric movement, but are also regarded as crucial reasons for the formation of extreme weather and climate anomalies. A large number of previous studies have shown that freezing rain and snowstorm events in the winter are closely related to the atmospheric low-frequency activities. For example, from late January to early February in 2008, an extreme persistent cold and heavy precipitation event occurred in China. Zhou et al. [15] proposed this event was related to the strong and stable maintenance of Eurasian blocking high. Ding [16] investigated the relationships between the Siberian High (SH) and cold surges, finding that the cold air propagates southward, mainly in 10-20 d low-frequency oscillation modes when cold surges occur. Gong and Ho [17] revealed the possible causes of wintertime temperatures in East Asia by considering the influence of intra-seasonal variation of the $\mathrm{SH}$ and Arctic oscillation.

In recent years, sub-seasonal prediction has become a difficult point in climate research [18,19], the study of atmospheric sub-seasonal oscillation is a bridge between weather and short-term climate prediction. It fills the gap between medium- and long-term weather prediction and seasonal prediction, which plays an important role in extended period forecast [20].

To improve the forecast timeliness of extreme weather and climate events, previous studies have often focused on finding predictive factors with pre-signal characteristics in various subsystems of atmospheric circulation systems [21,22]. Shi and Bueh [23] found that before the occurrence of WPECEs in China, the stratospheric geopotential height field at $100 \mathrm{hPa}$ always exhibited a strong positive anomaly, and the zonal wind at $200 \mathrm{hPa}$ on the northwest side of Lake Baikal has weakened significantly. In addition, as an important circulation system in the lower troposphere in winter, the East Asian winter monsoon is one of the important factors affecting the winter temperature change in China [24-26]. Moreover, the upper level jet over East Asia as an important part of the atmospheric circulation system in the mid-high latitude regions is also a crucial factor to the extreme low temperature events in winter. Therefore, the study of the relationships between lowfrequency oscillation and persistent extreme cold events is one of the key factors to develop the prediction capability of extended period. As an important part of the atmospheric circulation system in the mid-high latitude regions, by affecting the interactions among the circulation systems in different latitudes or the upstream and downstream circulation systems, the variation process of the upper level jet in different scales is closely related to the large-scale atmospheric circulation and the extreme low temperature events in winter. For instance, based on the analysis of several, typical, breaking low temperature record processes in China, it was found that the transport of eddy kinetic energy and transient disturbance by the upper level jet-corresponding to the record breaking cold processes in different regions-are significantly different. This means that the concurrent variation of the upper level jet on the sub-seasonal scale is closely related to the persistent anomaly cold events [27]. These concurrent variation relationships represent the integral structure and variation features of the atmospheric circulation over East Asia, which have crucial influence on extreme weather [28-30].

Therefore, it is of great significance to study the relationships between persistent cold events and East Asian upper level jet activities on the sub-seasonal scale for improving the prediction level of the extreme weather and climate in East Asia. In addition, the previous studies mainly focus on individual events, such as extreme cold and persistent rain and snow, but there are few studies on the sub-seasonal variation of upper level jet and winter persistent extreme cold events (WPECEs). This paper mainly studies the distribution and occurrence of WPECEs in China during the winter of 1961-2018, and analyzes the associations between the sub-seasonal variation of upper level jet and the atmospheric circulation in East Asia at mid-high latitude regions. Finally, the possible relationships between the sub-seasonal variation of upper level jet and WPECEs are revealed. 


\section{Data and Methods}

\subsection{Data}

The following datasets are used in this study: (1) daily mean temperature data of 2479 stations in China from 1961 to 2018, obtained from China Meteorological Data Service Center [31]. (2) Daily mean sea level pressure (SLP), $500 \mathrm{hPa}$ geopotential height and air temperature, horizontal and vertical wind at $300 \mathrm{hPa}$ and $850 \mathrm{hPa}$, which is performed at $2.5^{\circ} \times 2.5^{\circ}$ resolution and cover the period from 1 January 1961 to 31 December 2018, obtained from the National Centers for Environmental Prediction and National Centers for Atmospheric Research (NCEP/NCAR) reanalysis data [32].

\subsection{Methods}

\subsubsection{Recognition of the Winter Persistent Extreme Cold Event}

This paper defines that winter covers December in the current year to February in the following year (e.g., the winter of 1961 refers to December 1961 and January-February 1962). Refer to the methods of defining extreme low temperature events in previous relevant literature [33,34]. In this paper, the daily average temperature in winter of each station in China from 1961 to 2018 is ranked into an ascending order, and the 5th percentile value is taken as the extreme low temperature threshold of the station. Then, we studied the extreme cold events lasting at least 3 days in Xinjiang region when the daily average temperature was below the low temperature threshold, and calculated that the average duration of each persistent extreme cold event was $7.15 \mathrm{~d}$. This article also tests the sensitivity of the final results to other indices (e.g., at least 6 consecutive days and 8 consecutive days [35]), and the conclusions are not qualitatively different (see Section 3.1.1 for details). Therefore, if the daily average temperature of a station is lower than the extreme low temperature threshold for 7 consecutive days or more, it is considered that this single station winter persistent extreme cold event (WPECE) occurs.

\subsubsection{Brief Introduction of Research Methods}

Firstly, based on the daily mean temperature data of 2479 stations in China, we synthetically analyzed the basic distribution of WPECEs in China and the temperature variation characteristics of the key region when WPECE occurred. Moreover, with the method of synthetic analysis, the features of the atmospheric circulation, especially the upper level jet during WPECEs were further investigated. Moreover, for the results of the composite analysis, we conducted a confidence test at the $95 \%$ level. In addition, by using the method of power spectrum period analysis, the dominant period of upper level wind field variation in WPECEs was found. Filtering analysis was helpful to study the characteristics of different scale motions through scale separation, so it was widely applied to the study of atmospheric low-frequency changes [36-38]. In order to eliminate the influence of high-frequency weather systems, we used Butterworth band-pass filtering $[39,40]$ to retain the periods of 10-20 days in $300 \mathrm{hPa}$ wind field. Therefore, when synthetically analyzing the quasi-biweekly variations of atmospheric circulation and its relationship with WPECEs, we used the Butterworth band-pass filter-to-filter SLP field, $850 \mathrm{hPa}$ wind field, $500 \mathrm{hPa}$ and surface air temperature field, and $300 \mathrm{hPa}$ wind field for 10-20 days. At last, according to the latitude-time sections and longitude-time sections, we revealed the propagation characteristics of wind field, which influenced the WPECEs.

\section{Results}

\subsection{Basic Characteristics of WPECEs in China}

\subsubsection{Spatial Distribution of WPECEs}

The spatial distribution of winter average temperature, extreme low temperature threshold, and the WPECEs are shown in Figure 1. The distribution of the extreme low temperature threshold is consistent with that of the winter average temperature, and both are characterized by the "North Cold/ South Warm" pattern (Figure 1a,b). Moreover, the extreme low temperature threshold in the northern Xinjiang region and Heilongjiang 
province went down $-30^{\circ} \mathrm{C}$. Figure $1 \mathrm{c}-\mathrm{e}$ are the spatial distributions of the WPECE occurrence frequencies, which, respectively, represent three different indices: 7 consecutive days (the low temperature threshold is 5 th percentile), 6 consecutive days (the low temperature threshold is 10th percentile), 8 consecutive days (the low temperature threshold is 10th percentile). We can find that there is no qualitatively difference in the spatial distribution of the WPECE occurrence frequency in China. Therefore, considering the regional characteristics of Xinjiang (the average duration of each persistent extreme cold event is $7.15 \mathrm{~d}$ ), we select 7 days (the low temperature threshold is 5th percentile) as the standard (Figure 1c). From Figure 1c, it can be seen that the frequency of WPECEs is higher in most areas of central and south of Xinjiang and is relatively less in the southeast of Tibet Plateau, the east of North China Plain, and the coastal areas of eastern China, which is characterized by the "West More/East Less" pattern. It is worth noting that the WPECE in Xinjiang region has obvious regional differences, and occurs most frequently in the central region of Xinjiang. Next, we define the key area and key station for further analysis. According to the frequency of WPECEs, the area with the highest frequency of WPECEs is defined as the key area. The key area is chosen to be $37.5^{\circ}-42.5^{\circ} \mathrm{N}$ and $80^{\circ}-90^{\circ} \mathrm{E}$ (blue box region in Figure 1c). Moreover, Xinhe station, in the key area, WPECEs occurred most frequently from 1961 to 2018, which is identified as the key station. Thus, this paper focuses on the study of WPECEs in Xinjiang, China.

\subsubsection{Inter-Annual and Inter-Decadal Variations of the WPECEs}

To characterize the occurrence of WPECEs on different timescales and investigate the representativeness of the key station, we analyzed the inter-annual evolution of WPECEs at the key station and key area (Figure 2). From Figure 2, we can find that there are apparent inter-annual and inter-decadal differences in the occurrence of WPECEs in the key region. It should be noted that the WPECEs occurred frequently in the middle of 1970s and became active again in the early 2000s after experiencing an inactive period (mid-1980s to the late 1990s). Note that the situation at the key station is roughly the same. Therefore, the frequency of WPECEs in Xinjiang shows obvious inter-annual and inter-decadal differences during 1961-2018. Furthermore, it should be noted that the key station is very representative.
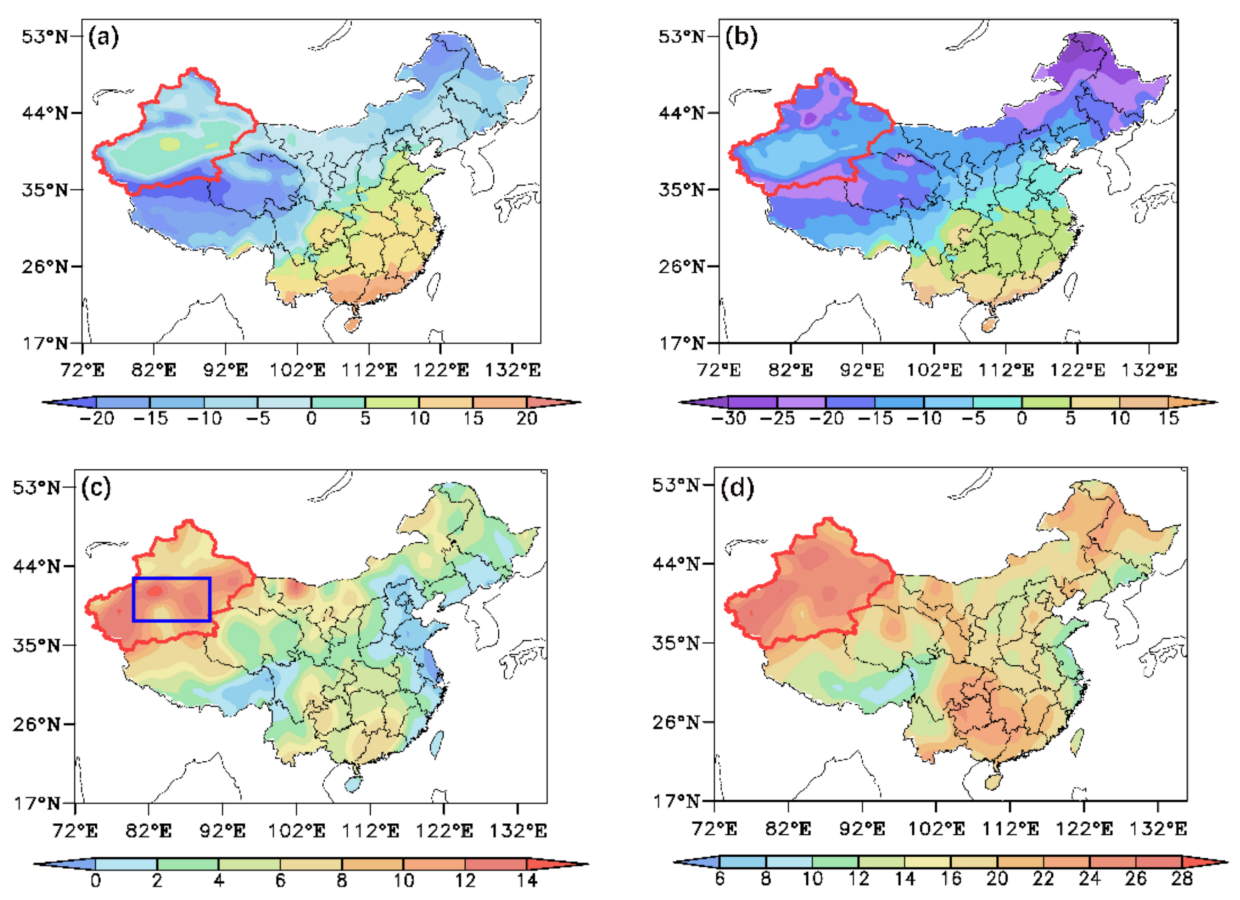

Figure 1. Cont. 


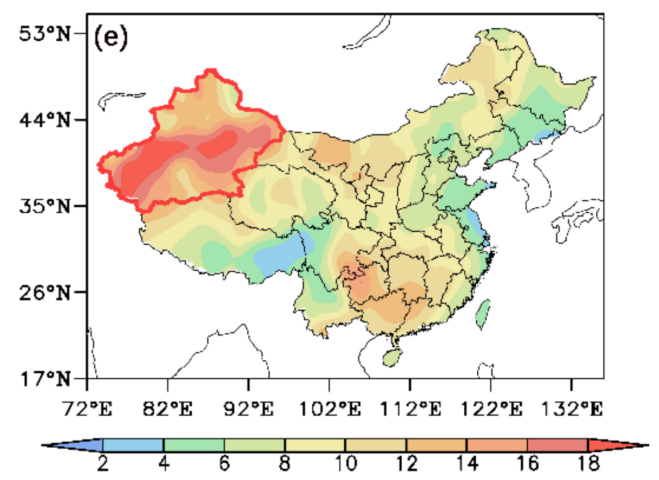

Figure 1. (a) The spatial distribution of winter average temperature (unit: ${ }^{\circ} \mathrm{C}$ ). (b) The spatial distribution of extreme low temperature threshold (unit: ${ }^{\circ} \mathrm{C}$ ). (c) The spatial distribution of the WPECEs occurrence frequency in China (the key area is highlighted with blue box region) (unit: times). (d) The spatial distribution of the WPECEs occurrence frequency in China with at least 6 consecutive days (the low temperature threshold is 10th percentile) (unit: times). (e) The spatial distribution of the WPECEs occurrence frequency in China with at least eight consecutive days (the low temperature threshold is 10th percentile) (unit: times). The position of Xinjiang has been marked with red bold line on the map.

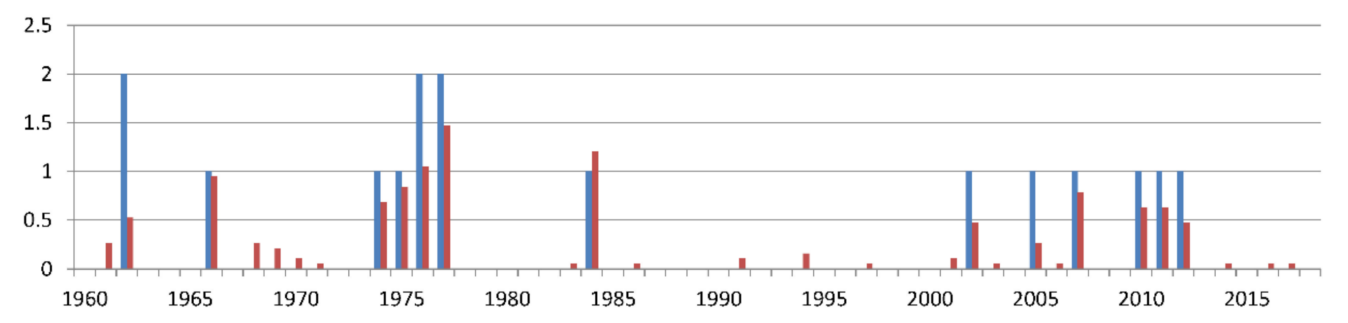

Figure 2. Inter-annual variation of WPECEs in the key area (red solid bars) and the key station (blue solid bars) in Xinjiang, China during 1961 to 2018 (units: times).

The daily evolution characteristics of WPECEs are further analyzed. As shown in Figure 2, the key station has experienced 16 WPECEs in the past 58 years. In order to find out the evolution characteristics of mean temperature when WPECE occurs, relying on the occurrence time of WPECEs of the key station, we depict the mean temperature variation in the key area each time WPECE occurs (Figure 3). It can be seen, during WPECEs, Xinjiang has experienced an evolution process of cooling first, and then warming up, which has a very obvious low-frequency oscillation.

\subsubsection{Characteristics of Atmospheric Circulation Corresponding to WPECEs}

Here, we synthesize the sea level pressure (SLP) field, $500 \mathrm{hPa}$ geopotential height field, $300 \mathrm{hPa}$ wind field, and their corresponding abnormal fields when the key station WPECE occurred. Figure 4a displays the distribution of the composite SLP field and the related SLP anomalies over the East Asia for 16 WPECEs. As seen in Figure 4a, the Siberian High (SH) strengthened and expanded over Eurasia, with the anomalous high SLP extending southeast from the Ural Mountains to the south of China. The composited $500 \mathrm{hPa}$ geopotential height field and the corresponding air temperature anomalies in the WPECEs are depicted in Figure $4 \mathrm{~b}$. The composited air temperature anomalies from high latitude to low latitude are characterized by the "War-Cold-Warm" pattern. Moreover, this pattern is distinct from the typical feature of air temperature in the mid-troposphere in extreme cold events, which will inevitably change the meridional gradient of temperature and affect the baroclinicity of the atmosphere. In addition, this combination of the anomalous low temperature and tilted trough is beneficial to deepen the trough. 

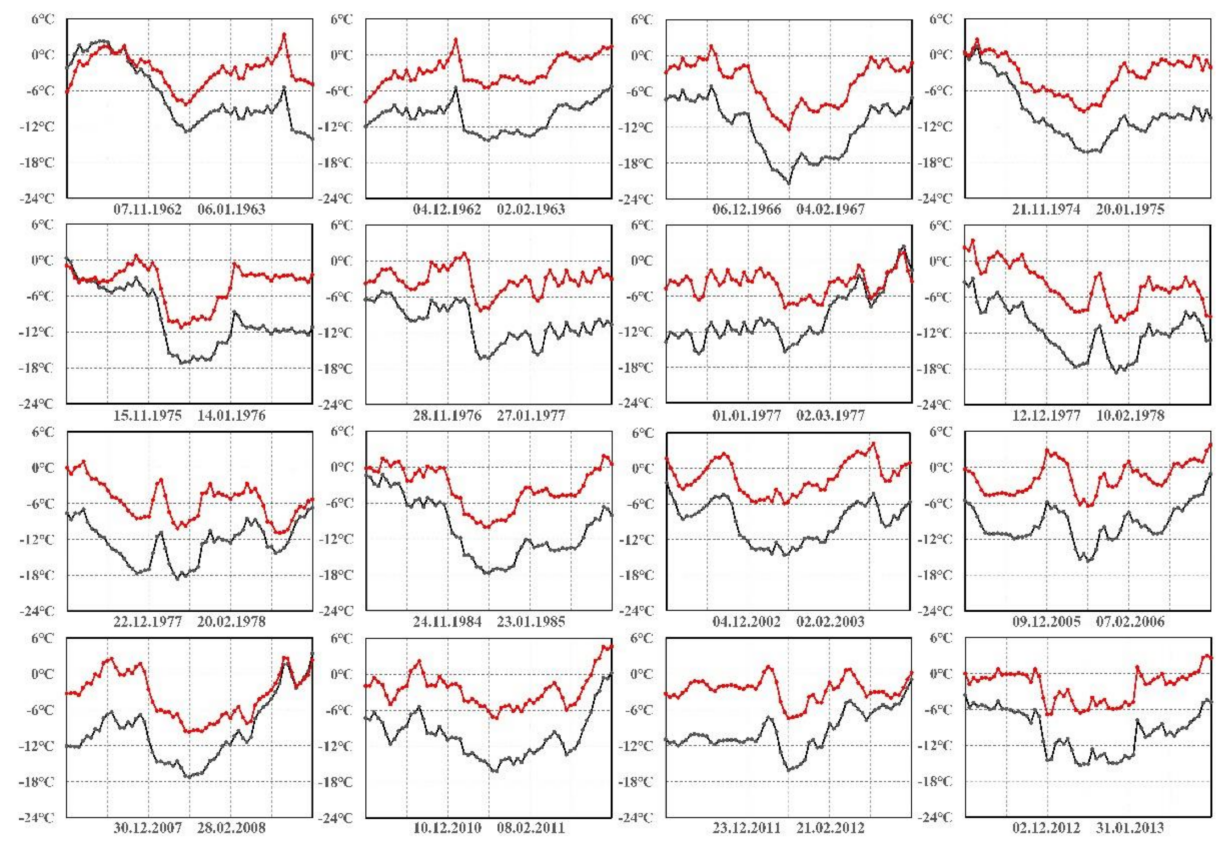

Figure 3. The evolution of regional mean temperature in the key area of 16 WPECEs (unit: ${ }^{\circ} \mathrm{C}$ ). The black line is the temperature absolute values, and the red line is the temperature anomaly.
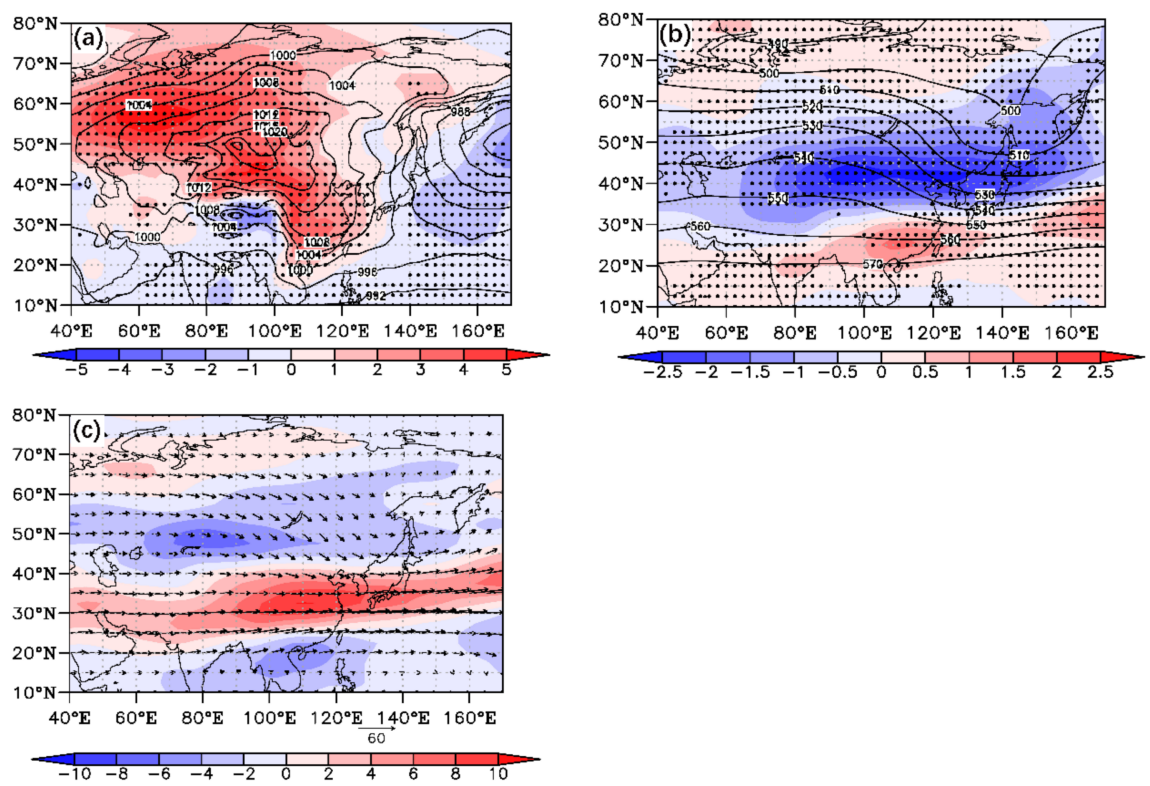

Figure 4. When WPECE occurs in key station: (a) SLP field (contour) and the corresponding SLP anomalies (shaded) (units: hPa); (b) $500 \mathrm{hPa}$ geopotential height field (contour) (unit: gpm) and the corresponding air temperature anomalies (shaded) (units: ${ }^{\circ} \mathrm{C}$ ); (c) $300 \mathrm{hPa}$ wind field (arrow) and zonal wind anomalies (shaded) (units: $\mathrm{m} / \mathrm{s}$ ) in WPECEs. The doted regions are for values significant at or above the $95 \%$ confidence level.

The East Asian upper jet is a narrow strong belt in the upper troposphere and lower stratosphere of East Asia. The wind speed is generally greater than $30 \mathrm{~m} / \mathrm{s}$, accompanied by strong horizontal and vertical wind shear and atmospheric baroclinic. Its position and intensity have obvious seasonal variation. There are two branches of narrow and strong jet streams are referred to the East Asian subtropical jet (EASJ) and polar front jet (PFJ). The latitude corresponding to the strongest westerly wind speed is defined as the jet axis. In order to examine the westerly wind speed distribution at upper level in WPECEs, the 
composited wind speed distribution, and the related anomaly at $300 \mathrm{hPa}$ level are performed in Figure 4c. The jet axis is situated over northwest Pacific Ocean to the south of Japan $\left(25^{\circ}-35^{\circ} \mathrm{N}\right)$, where the EASJ center is located. It is found that in the mid-high latitude regions, a negative anomaly westerly wind appears over the north of Lake Balkhash, and a positive anomaly to the middle-lower reaches of the Yangtze River region.

To conclude, the amplified and expanded $\mathrm{SH}$, the troughs and ridges extending from northeast to southwest at the middle troposphere, and a strong EASJ accompanied by a weak PFJ are the main atmospheric circulation features of WPECEs in Xinjiang.

In order to detect the variation characteristics of the upper level jet when the WPECE occurs, the differences of the upper level jet corresponding to the climatological mean winter and the winter of WPECEs are compared.

As indicated in Figure 5a, the zonal westerly wind $(u>0)$ is mainly located in the middle and high latitudes, while the zonal easterly wind $(u<0)$ is mainly located in the equatorial and polar regions. We can find that there is a strong westerly belt from the Arabian Peninsula to the subtropical northwest Pacific Ocean in the upper troposphere, by synthetically analyzing the distribution of the East Asian upper level jet in climatological mean winter. The strong westerly belt, with the largest wind speed over the northwest Pacific Ocean, is well-known as the winter Asian jet. Further, synthetic analyzing of the standard deviation of daily zonal wind field in climatological mean winter (Figure 5b) shows that the PFJ from the west European coast to the north of Balkhash Lake and the EAPJ from the east of Japan are very active, with a wide range of activities and obvious characteristics of intra-seasonal variation. Figure $5 \mathrm{c}$ displays the mean zonal wind anomaly in the winters of WPECE year. The PFJ in the upper troposphere near Lake Balkhash is abnormally weak, while the anomaly of EASJ is intense near $30^{\circ} \mathrm{N}$. To further understand the activities of the upper level jet, we attempt to display that the zonal wind mean standard deviation anomaly field in Figure 5d. It is worth noting that there is a strong intra-seasonal variation of the PFJ in the northeast of Lake Balkhash, while the EAPJ variability is more reduced. Consequently, in the following section, we will focus on the relationship between the WPECEs in Xinjiang and the intra-seasonal activity of PFJ.
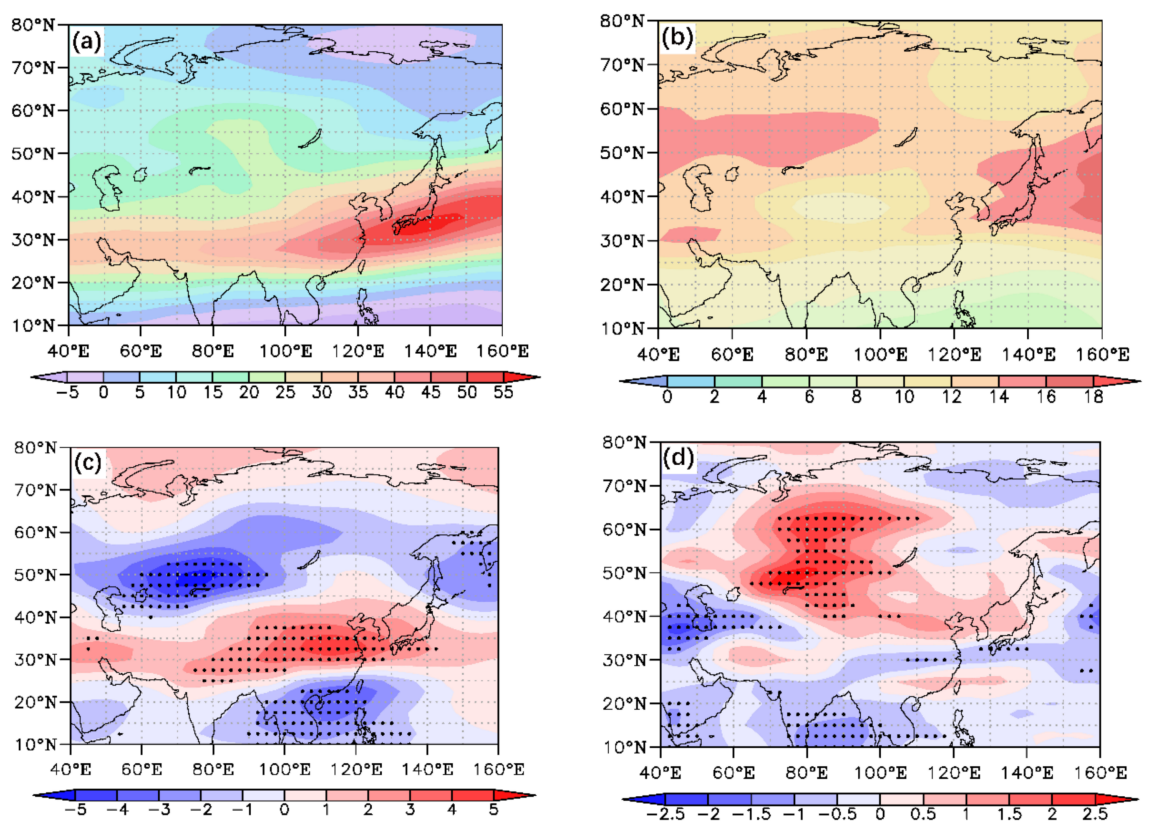

Figure 5. (a) The $300 \mathrm{hPa}$ zonal mean wind field in climatological mean winter; (b) the standard deviation of $300 \mathrm{hPa}$ daily zonal wind field in climatological mean winter; (c) the deviation of $300 \mathrm{hPa}$ mean zonal wind field in WPECE winter; (d) the standard deviation anomaly of $300 \mathrm{hPa}$ mean zonal wind field in WPECE winter (units: $\mathrm{m} / \mathrm{s}$ ). The doted regions are for values significant at or above the 95\% confidence level. 


\subsection{Relationships between WPECEs and PFJ Intra-Seasonal Oscillation in Xinjiang, China}

3.2.1. Characteristics of Low-Frequency Oscillation of PFJ in the Years of WPECEs

As shown in Figure $5 \mathrm{~d}$, there is an obviously strong intra-seasonal variation of the PFJ at $80^{\circ}-90^{\circ} \mathrm{E}$ and $40^{\circ}-60^{\circ} \mathrm{N}$. To further find out the activity characteristics of the PFJ on the sub-seasonal scale, we select $80^{\circ}-90^{\circ} \mathrm{E}$ and $40^{\circ}-60^{\circ} \mathrm{N}$ as the key area of jet. Through using one-dimensional continuous power spectrum, we analyze the dominant period of $300 \mathrm{hPa}$ zonal wind field in the key area of jet during the years of WPECEs (Figure 6a). The result indicates that the intra-seasonal variation is mainly characterized by peak in 10-20 days and its power spectral density has passed the significance test of $\alpha=0.05$. This is consistent with the conclusion of Ding [16] that the cold air propagates southward mainly in 10-20 d low-frequency oscillation mode. In order to eliminate the influence of high-frequency weather systems, we use Butterworth band-pass filtering to retain the periods of 10-20 days in $300 \mathrm{hPa}$ wind field. In Figure $6 \mathrm{~b}$, the standard deviation of filtered $300 \mathrm{hPa}$ zonal wind reflects an obviously strong QBWO in the year of WPECE over Lake Balkhash. It is further demonstrated that the WPECE in Xinjiang is closely related to the QBWO of the PFJ.
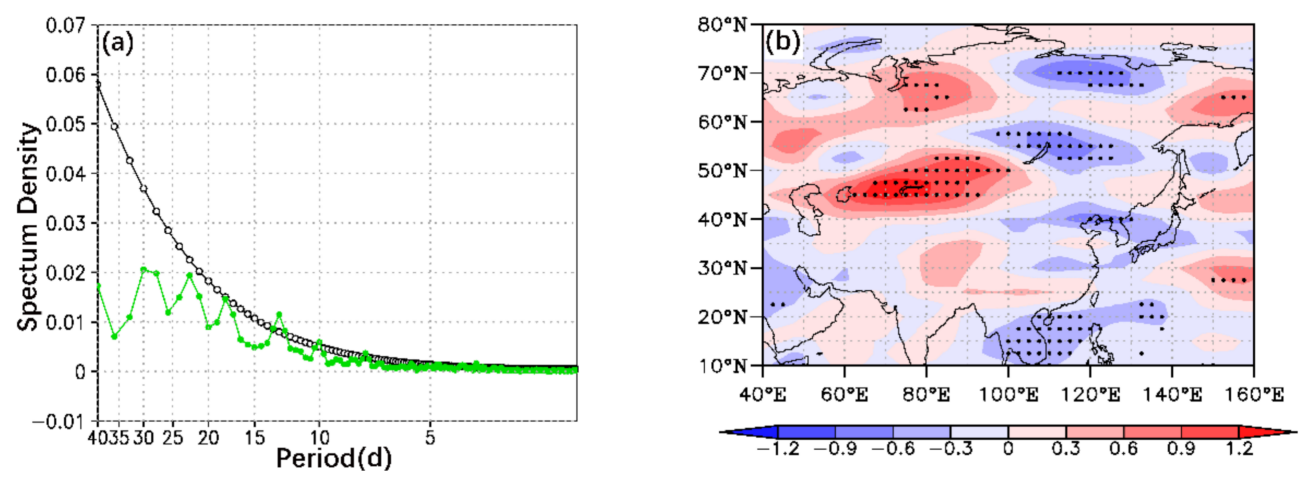

Figure 6. (a) The power spectrum of $300 \mathrm{hPa}$ zonal wind field in the key area of PFJ during the years of WPECEs (green line is the spectrum density, black line means $95 \%$ red noise test). (b) The synthesis of the anomaly of the 10-20 d filtered zonal wind standard deviation of $300 \mathrm{hPa}$ during the years of WPECEs (unit: $\mathrm{m} / \mathrm{s}$ ). The doted regions are for values significant at or above the $95 \%$ confidence level.

\subsubsection{The QBWO of PFJ during WPECE}

Hereafter, day 0 refers to the mean minimum temperature day in the key area of Xinjiang and day $-\mathrm{N}(\mathrm{N})$ refers to $\mathrm{N}$ days before (after) day 0 in WPECE. Figure 7a shows the evolution of the zonal wind 15 days before and after the WPECE in the key region of $\mathrm{PFJ}$ at $300 \mathrm{hPa}\left(80-90^{\circ} \mathrm{N}, 40-60^{\circ} \mathrm{E}\right)$. At day -0 , the quasi-biweekly scale zonal wind begins to weaken. Then, it turns to easterly zonal wind at day -6 , and reaches the weakest at day -3 . After day 0 , the easterly zonal wind starts to weaken and turns to westerly zonal wind at day 2. Consistent with the quasi-biweekly scale zonal wind in the region of PFJ, the unfiltered PFJ begins to weaken at day -9 and reaches the weakest at day -4 . The evolution of mean temperature field in the key surface area before and after 15 days in WPECE is presented in Figure 7b. On the quasi-biweekly scale, the mean temperature starts to decrease at day -7 and drops to zero at day -3 . It is noteworthy that the weakening of the quasi-biweekly scale PFJ approximately 3 days prior to the decrease of surface air temperature and approximately 10 days prior to the mean minimum temperature day. These characteristics between the QBWO of PFJ and WPECEs provide significant clues for the early prediction of WPECEs in Xinjiang, China. 

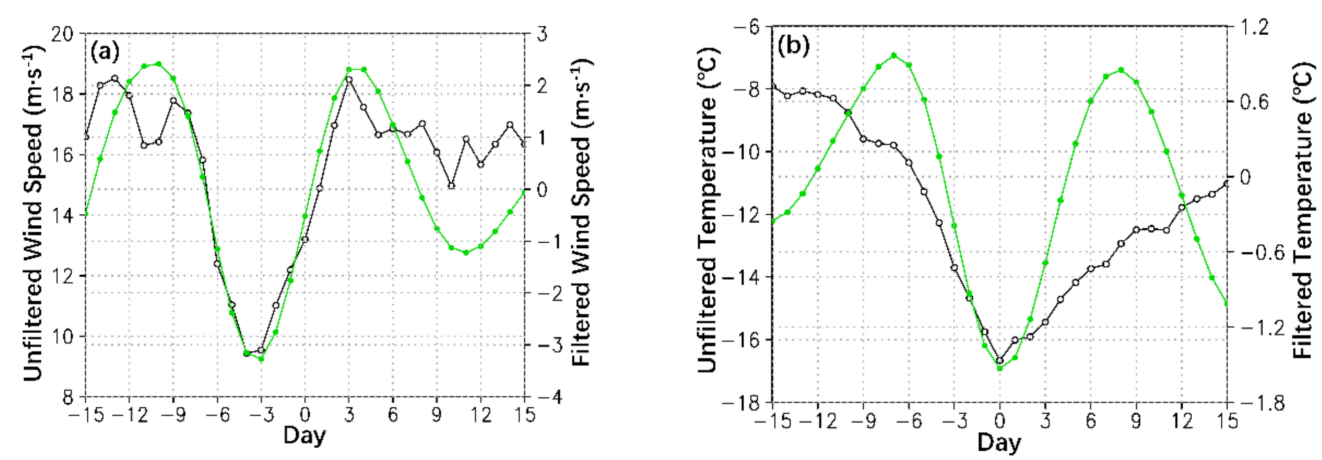

Figure 7. (a) Time evolution of the zonal wind (black line) and the 10-20 d filtered zonal wind (green line) in the upper level wind field key area 15 days before and after the WPECE. (b) Time evolution of mean air temperature (black line) and the 10-20 d filtered air temperature (green line) in the surface key area 15 days before and after the WPECE.

\subsubsection{The Quasi-Biweekly Variations of Atmospheric Circulation}

Previous studies have focused on the atmospheric circulation may show distinct precursory signals before the occurrence of extensive and persistent extreme cold events.

To underline the connection between atmospheric circulation and persistent extreme cold events more clearly, based on the daily mean temperature data of 2479 stations in China, we first analyzed the deviation of surface air temperature field and 10-20 d filtered surface air temperature field when WPECE occurred (Figure 8). From day -7 to day -5 (Figure 8a,b), the intensity and scope of abnormal low temperature in Xinjiang expanded, and low-frequency air temperature in Northern Xinjiang dropped to below zero. At day -3 (Figure $8 \mathrm{c}$ ), the low-frequency air temperature dropped to below zero in the whole Xinjiang region. Then, the negative anomaly value of surface air temperature in the whole Xinjiang region further increased and low-frequency air temperature decreased to a minimum at day -1 (Figure $8 \mathrm{~d}$ ). Subsequently, with the end of the WPECE, the lowfrequency air temperature gradually rose, and the degree of abnormal low temperature in Xinjiang weakened. We noticed that when the WPECE occurred, the low-frequency air temperature first affected the northern Xinjiang region (Figure 8). Then, the cold air propagated southward from the northwest to the south of China, affecting most parts of China, while the cooling situation in Xinjiang region was the most significant. Therefore, in the following, we further analyze the impact of quasi-biweekly variations of atmospheric circulation on WPECEs.

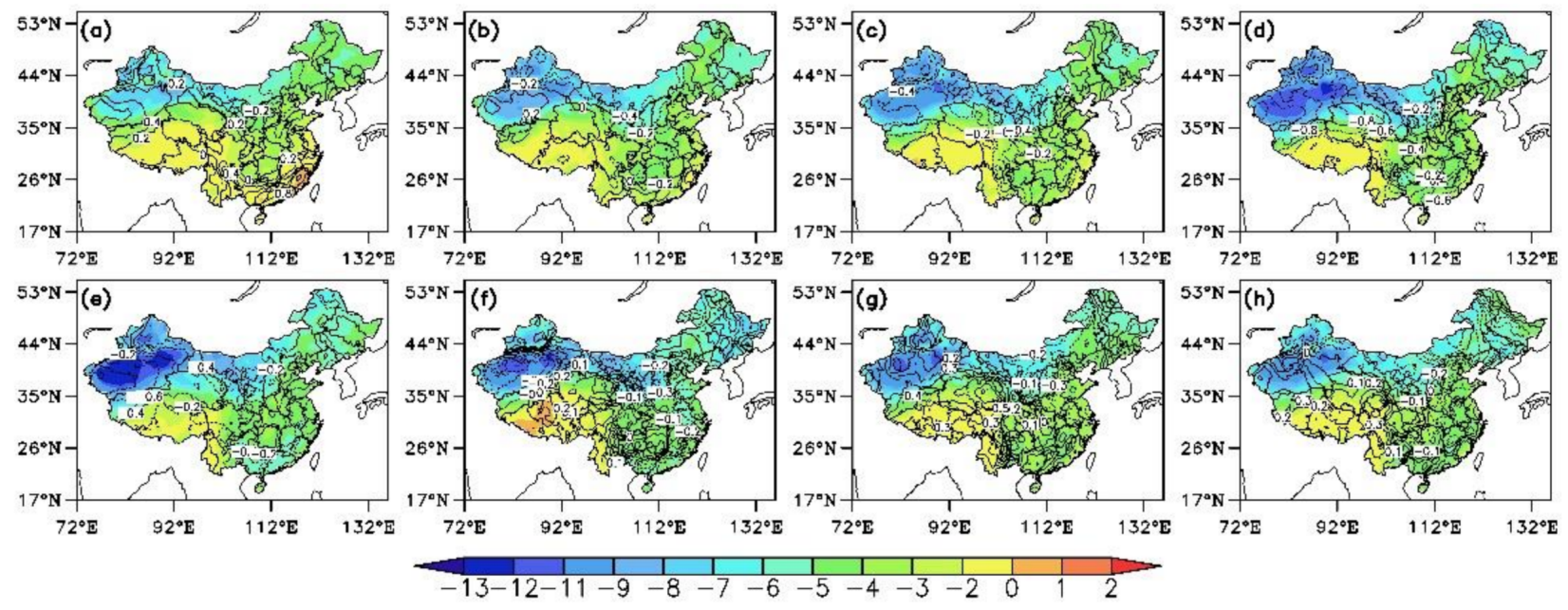

Figure 8. Composition of the deviation of the unfiltered temperature field (shaded, unit: ${ }^{\circ} \mathrm{C}$ ) and the $10-20 \mathrm{~d}$ filtered surface air temperature field (contour, unit: $\left.{ }^{\circ} \mathrm{C}\right) 7$ days before and after day 0 in WPECE $((\mathbf{a}-\mathbf{h}):-7 d,-5 d,-3 d,-1 d, 1 d, 3 d, 5 d, 7 d)$. 
To detect the quasi-biweekly evolution of the atmospheric circulation, we filtered the wind fields at $300 \mathrm{hPa}$ and $850 \mathrm{hPa}$, the temperature field at $500 \mathrm{hPa}$, and the SLP field for 10-20 days period, and showed the filtered composite fields of $300 \mathrm{hPa}$ zonal wind, wind vector, and temperature at $500 \mathrm{hPa}$ in Figure 9. Figure 9a shows that the key area, which is located in the northeast of Lake Balkhash, established a cold center with cyclonic circulation. The northwest part of the abnormal cold center was dominated by northerly wind, which was favorable to southward propagation at day -7 . At day -5 (Figure $9 b$ ), the strength of the cold center expanded and continued to move southeast. Consistent with the cold center, the abnormal zonal easterly wind field moved southeast with the wind speed increasing. At day -3 (Figure 9c), the cold center continued to move southeast to the Mongolian Plateau, while its intensity and the cyclonic circulation weakened. The zonal easterly wind field at the northwest of the cyclone moved to the north of Xinjiang, and the wind speed increased to the maximum. Then, the zonal easterly wind continued moving southward, with weakening wind speed, and the weakening cold center moved eastward at day -1 (Figure 9d). Replacing the cold air mass and the cyclone, the warm center and anticyclone circulation was located east of Lake Balkhash (Figure 9e), and subsequently, the zonal westerly strengthened (Figure 9f). At day 7, the anticyclone circulation system disappeared in the region of Lake Balkhash (Figure 9g).
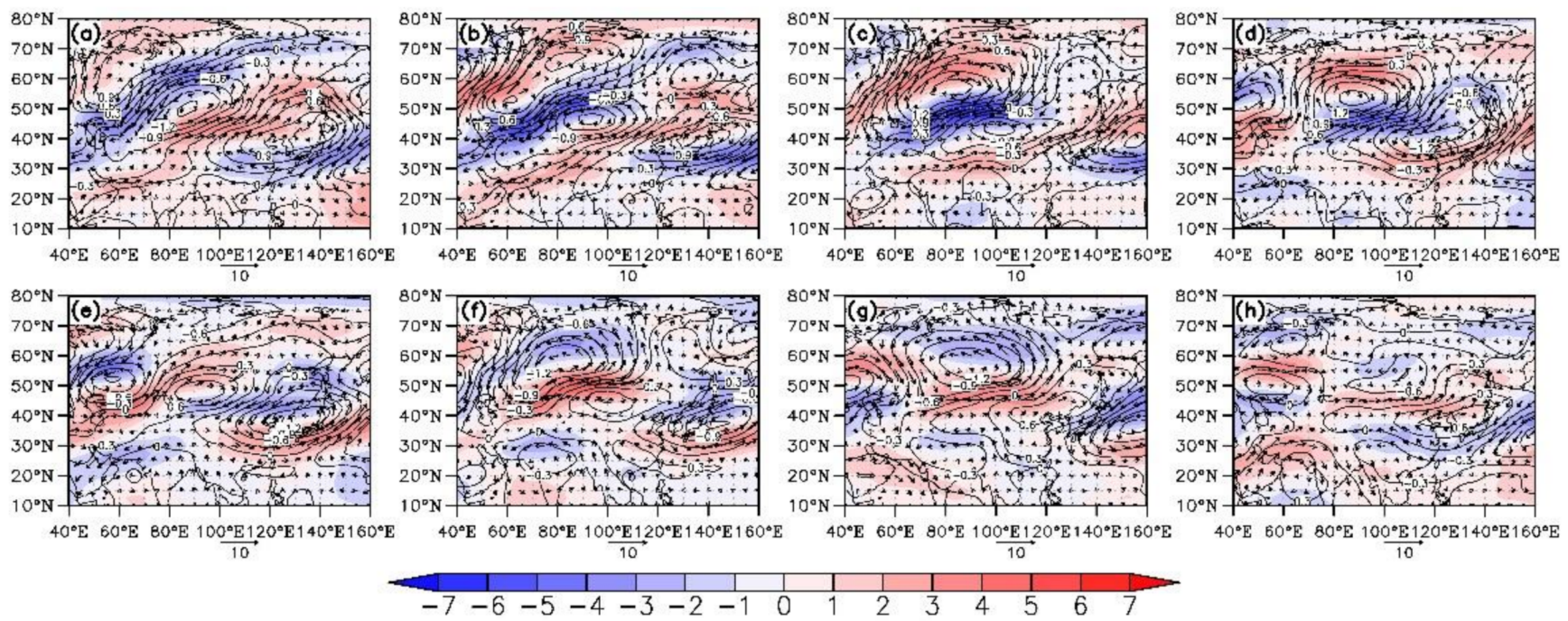

Figure 9. Composition of the $300 \mathrm{hPa}$ 10-20 d filtered zonal wind field (shaded, unit: $\mathrm{m} / \mathrm{s}$ ), $300 \mathrm{hPa}$ full wind speed (arrow, unit: $\mathrm{m} / \mathrm{s}$ ), and the $500 \mathrm{hPa}$ temperature field (contour, unit: $\left.{ }^{\circ} \mathrm{C}\right) 7$ days before and after day 0 in WPECE $((\mathbf{a}-\mathbf{h}):-7 \mathrm{~d},-5 \mathrm{~d}$, $-3 \mathrm{~d},-1 \mathrm{~d}, 1 \mathrm{~d}, 3 \mathrm{~d}, 5 \mathrm{~d}, 7 \mathrm{~d})$.

As an important circulation system in the lower troposphere in winter, the East Asian Winter Monsoon carried high latitude cold air southward with high wind speed, which made the temperature drop sharply. Therefore, the East Asian winter monsoon was one of the important factors affecting the winter temperature change in China. To analyze the characteristics of the low-frequency circulation during the WPECEs in Xinjiang, we show the evolution of 10-20 d filtered SLP field, wind field at $850 \mathrm{hPa}$, and unfiltered SLP filed, before and after the WPECE, in Figure 10. In Figure 10a, there is an abnormally strong low-frequency high over the west side of Ural Mountain and near the sea of Okhotsk at day -7 . At day -5 , Figure $10 \mathrm{~b}$ depicts that the low-frequency high near the Ural Mountain was strengthened, and its influence expanded and extended eastward to the Mongolian Plateau. Moreover, the anticyclone circulation strengthened. At day -3 (Figure 10c), with accumulation of the strong cold air, the low-frequency high further increased. The north wind component in front of the anticyclone also strengthened, which was beneficial to the cold air rapidly southward. Under the guidance of northerly airflow, cold air burst southward, rapidly affecting Xinjiang, Qinghai, and most areas of southern China (Figure 10d). 
Then, the cold air moved southward, and the north part of Lake Balkhash was controlled by a low pressure center and cyclonic circulation (Figure 10e). With the intensification, the southward expansion and the extinction of low pressure system (Figure 10f-h), the WPECE process ended.
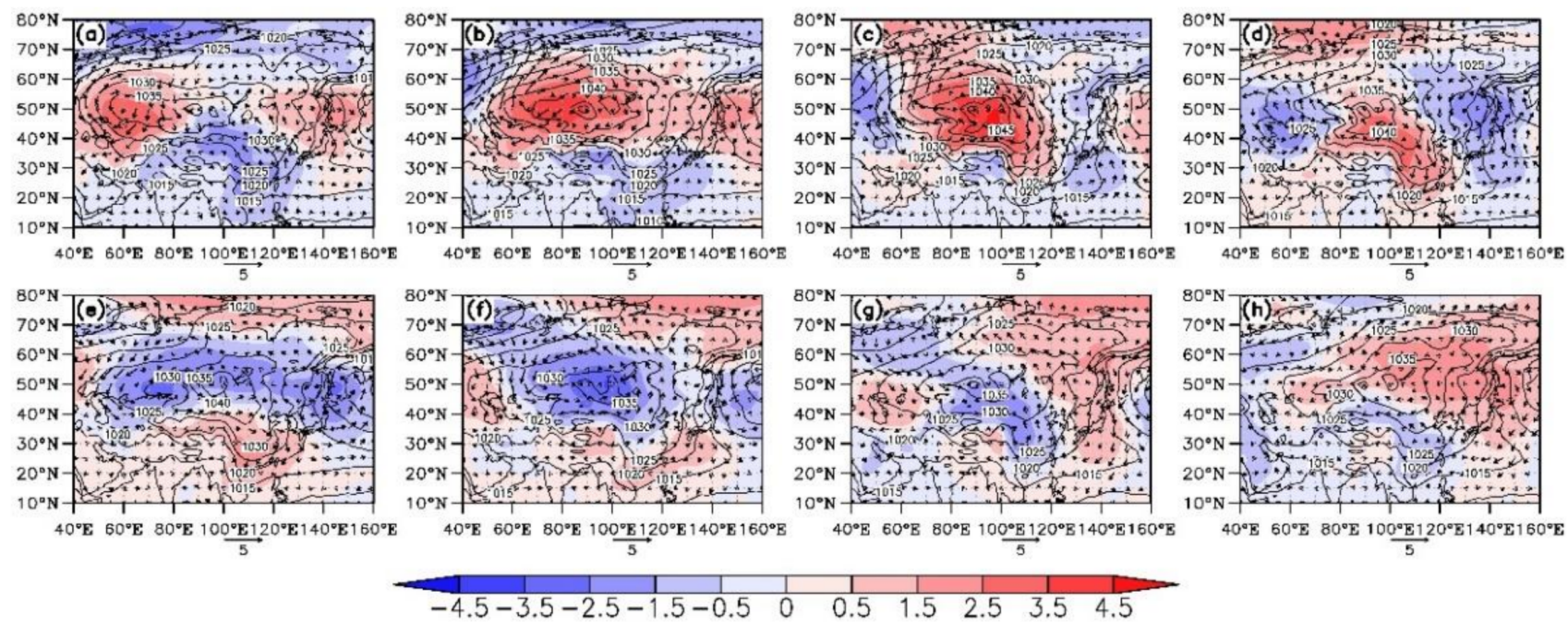

$40^{\circ} \mathrm{E} 60^{\circ} \mathrm{E} 80^{\circ} \mathrm{E} 100^{\circ} \mathrm{E} 120^{\circ} \mathrm{E} 140^{\circ} \mathrm{E} 160^{\circ} \mathrm{E}$

Figure 10. Composition of the 10-20 d filtered SLP field (shaded, unit: hPa), $850 \mathrm{hPa}$ wind field (arrow, unit: $\mathrm{m} / \mathrm{s}$ ), and the unfiltered SLP field (contour, unit: hPa) 7 days before and after day 0 in WPECE ((a-h): $-7 \mathrm{~d},-5 \mathrm{~d},-3 \mathrm{~d},-1 \mathrm{~d}, 1 \mathrm{~d}, 3 \mathrm{~d}, 5 \mathrm{~d}, 7 \mathrm{~d})$.

\subsubsection{The Propagation of PFJ QBWO}

The time-latitude sections $\left(80^{\circ}-90^{\circ} \mathrm{E}\right.$ mean) of the filtered $500 \mathrm{hPa}$ geopotential height and the $850 \mathrm{hPa}$ meridional wind near the surface in the PFJ key region are shown in Figure 11a,b. The $500 \mathrm{hPa}$ geopotential height experienced a quasi-biweekly phase transition, which was from the negative phase to the positive phase from day -9 to day -3 . The $10-30 \mathrm{~d}$ filtered geopotential height anomaly propagated from high latitudes to mid-latitudes and reached its strongest near the polar front area. Before the extreme low temperature, a strong quasi-biweekly scale northerly anomaly appeared in the polar front area and its south (Figure $11 \mathrm{~b})$. Figure $10 \mathrm{c}, \mathrm{d}$ are the time-longitude section $\left(40^{\circ}-60^{\circ} \mathrm{N}\right.$ mean) and time-latitude section $\left(80^{\circ}-90^{\circ} \mathrm{E}\right.$ mean) of the filtered $300 \mathrm{hPa}$ zonal wind. From day -9 to day -3 , the quasi-biweekly zonal easterly wind propagated eastward from $40^{\circ} \mathrm{E}$ to $85^{\circ} \mathrm{E}$ approximately (Figure 11c), and propagated southward from $80^{\circ} \mathrm{N}$ to $50^{\circ} \mathrm{N}$, with the intensification of the wind (Figure 10d). Therefore, the intensification of the pressure at $500 \mathrm{hPa}$, the strong meridional wind at $850 \mathrm{hPa}$, and the eastward and southward propagation of quasi-biweekly PFJ, were the precursors of the WPECEs in Xinjiang, China. 

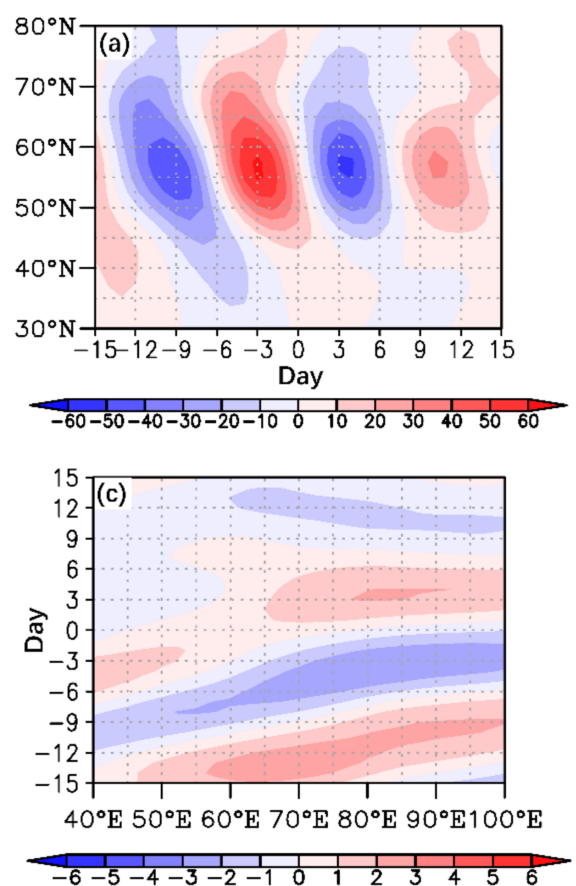

Figure 11. (a) The time-latitude section $\left(80^{\circ}-90^{\circ} \mathrm{E}\right)$ of the filtered $500 \mathrm{hPa}$ geopotential height; (b) the time-latitude section $\left(80^{\circ}-90^{\circ} \mathrm{E}\right)$ of the filtered $850 \mathrm{hPa}$ meridional wind; (c) the time-longitude section $\left(40^{\circ}-60^{\circ} \mathrm{N}\right)$ of the filtered $300 \mathrm{hPa}$ zonal wind; (d) the time-latitude section $\left(80^{\circ}-90^{\circ} \mathrm{E}\right)$ of the filtered $300 \mathrm{hPa}$ zonal wind 15 days before and after the WPECE.

\section{Discussion}

In this paper, we investigate the associations between the QBWO of the PFJ and the WPECEs in Xinjiang during 1961-2018, based on the daily mean temperature data and reanalysis data. In the research on the above issues, many related research papers used different data and analysis methods. However, the results show encouraging consistency in many aspects. The following is a brief description of them.

In Figure $4 b$, the troughs and ridges extend from northeast to southwest at the middle troposphere over the East Asia at the middle troposphere, which corresponds well to one of the key circulation features of WPECEs, as Bueh et al. [41], Wang et al. [42], and Fu et al. [43] have demonstrated.

In Figure 4c, the "Strong EASJ/Weak PFJ" pattern contributes to cold conditions when WPECE occurs, which is supported by Zhang and Chen [29].

In Figure 10, we investigate the characteristics of the low-frequency circulation, and find that the north wind component in front of the anticyclone is beneficial to the cold air southward. This result is consistent with Yu and Gao [44], who demonstrated that the anomalous northerly wind ushering the high latitude cold air southward is the key reason to the outbreak of persistent cold events.

Through the analysis of this article, we find that there are obvious interdecadal differences in the WPECEs in Xinjiang. The WPECEs occurred frequently in the middle of 1970s and became active again in the early 2000s after experiencing an inactive period (mid-1980s to the late 1990s). Therefore, the influence of the interdecadal background variations of atmospheric circulation on the WPECEs will be investigated in future work.

\section{Conclusions}

Based on the daily mean temperature data of 2479 stations in China and NCEP/NCAR reanalysis data, we analyzed the dominant circulation characteristics of WPECEs (equal or greater than 7 days) in Xinjiang region on a quasi-biweekly scale, and revealed the basic characteristics of the WPECEs in winter in Xinjiang, and their associations with the QBWO of the PFJ. The results show that there are very significant inter-annual and inter-decadal 
differences in WPECE frequency in Xinjiang region, which are closely related to the QBWO of the PFJ. When the WPECE occurs, the SH and the EASJ are strengthened, the intensity of the PFJ is weak, while the QBWO of the PFJ jet is strong. The anomalous quasi-biweekly zonal wind accompanied by quasi-weekly geopotential height anomaly propagates southward from the polar region to the key area of jet. Before the WPECE, the PFJ changed from the westerly anomaly to the easterly anomaly. Moreover, the intensity of the PFJ weakened, obviously, the meridional circulation developed, and the surface north wind strengthened, resulting in persistent cooling of the surface. With the continuous decrease of the temperature in the Xinjiang region, the anomalous easterly wind transforms into the anomalous westerly wind in the upper level, corresponding to the PFJ strengthening again, and the WPECE process ends. Furthermore, it is noteworthy that the PFJ begins to weaken at day -10 and reaches the weakest at day -3 . Therefore, the QBWO of the PFJ can be regarded as the precursory signal of the occurrence of the WPECE in Xinjiang region.

Author Contributions: Conceptualization, J.J. and S.Y.; methodology, J.J.; writing-original draft preparation, J.J.; writing - review and editing, S.Y.; project administration, S.Y.; funding acquisition, S.Y. All authors have read and agreed to the published version of the manuscript.

Funding: This research was funded by National Natural Science Foundation of China, grant number 41,930,969, 41,775,096, National Key Research and Development Program of China, grant 2018YFC1505802, and College Student Innovation and Entrepreneurship Training Program, grant number $202010300020 Z$.

Institutional Review Board Statement: Not applicable.

Informed Consent Statement: Not applicable.

Data Availability Statement: The data presented in this study are available upon request from the corresponding author.

Acknowledgments: We are very grateful to the three anonymous reviewers whose kind and valuable comments greatly improved the quality of the paper. We thank Huang Qian for his patient guidance. We also thank China Meteorological Data Service Center for providing observational data and the National Centers for Environmental Prediction and National Centers for Atmospheric Research (NCEP/NCAR) for providing the reanalysis data.

Conflicts of Interest: The authors declare no conflict of interest and that no personal circumstances or interests inappropriately influenced the representation or interpretation of the reported research results.

\section{References}

1. Climate Change 2013: The Physical Science Basis. Available online: http://www.climatechange2013.org/images/report/WG1 AR5_ALL_FINAL.pdf (accessed on 1 October 2013).

2. Wen, M.; Yang, S.; Kumar, A.; Zhang, P.Q. An analysis of the large-scale climate anomalies associated with the snowstorms affecting china in January 2008. Mon. Weather Rev. 2009, 137, 1111-1131. [CrossRef]

3. Sun, J.H.; Zhao, S.X. The Impacts of Multiscale Weather Systems on Freezing Rain and Snowstorms over Southern China. Weather Forecast. 2010, 25, 388-407. [CrossRef]

4. Wang, Z.Y.; Ding, Y.H.; Zhou, B.T.; Chen, L.J. Comparison of two severe low-temperature snowstorm and ice freezing events in China: Role of Eurasian mid-high latitude circulation patterns. Int. J. Climatol. 2020, 40, 3436-3450. [CrossRef]

5. Chen, J.H.; Jiang, H.; Wu, L.; Liao, X.; Lu, Y.N.; Tao, X.Q.; Deng, P.F.; Long, Y.; Huang, H.L. Association of ischemic and hemorrhagic strokes hospital admission with extreme temperature in Nanchang, China-A case-crossover study. J. Clin. Neurosci. 2017, 43, 89-93. [CrossRef]

6. Luo, Y.X.; Li, H.B.; Huang, F.F.; Van Halm-Lutterodt, N.; Xu, Q.; Wang, A.X.; Guo, J.; Tao, L.X.; Li, X.; Liu, M.Y.; et al. The cold effect of ambient temperature on ischemic and hemorrhagic stroke hospital admissions: A large database study in Beijing, China between years 2013 and 2014-Utilizing a distributed lag non-linear analysis. Environ. Pollut. 2018, 232, 90-96. [CrossRef]

7. Powell, J.P.; Reinhard, S. Measuring the effects of extreme weather events on yields. Weather Clim. Extrem. 2016, 12, 69-79. [CrossRef]

8. Hanefeld, C.; Klaaßen-Mielke, R.; Miebach, J.; Muthers, S.; Haschemi, A.; Trampisch, H.; Kloppe, C.; Matzarakis, A.; Krogias, C.; Schroeder, C. Influence of extreme weather conditions on the deployment volume of emergency medical services. Med. Klin. Intensivmed. Notfmed. 2019, 116, 154-160. [CrossRef]

9. Madden, R.A.; Julian, P.R. Detection of a 40-50 Day Oscillation in the Zonal Wind in the Tropical Pacific. J. Atmos. Sci. 1971, 28, 702-708. [CrossRef] 
10. Madden, R.A.; Julian, P.R. Description of Global-Scale Circulation Cells in the Tropics with a 40-50 Day Period. J. Atmos. Sci. 1972, 29, 1109-1123. [CrossRef]

11. Anderson, J.R.; Rosen, R.D. The latitude-height structure of 40-50 day variations in atmospheric angular momentum. J. Atmos. Sci. 1983, 40, 1584-1591. [CrossRef]

12. Li, C.Y.; Wu, P.L. An Observational Study of the 30-50 Day Atmospheric Oscillations Part I: Structure and Propagation. Adv. Atmos. Sci. 1990, 7, 294-304. [CrossRef]

13. Krishnamurti, T.N.; Jayakumar, P.K.; Sheng, J.; Surgi, N.; Kumar, A. Divergent Circulations on the 30 to 50 Day Time Scale. J. Atmos. Sci. 1985, 42, 364-375. [CrossRef]

14. Krishnamurti, T.N.; Gadgil, S. On the structure of the 30 to 50 day mode over the globe during FGGE. Tellus 1985, 37A, 336-360. [CrossRef]

15. Zhou, W.; Chan, J.C.L.; Chen, W.; Ling, J.; Pinto, J.G.; Shao, Y. Synoptic-scale controls of persistent low temperature and icy weather over southern China in January 2008. Mon. Weather Rev. 2009, 137, 3978-3991. [CrossRef]

16. Ding, Y.H. Build-Up, Air Mass Transformation and Propagation of Siberian High and Its Relations to Cold Surge in East Asia. Meteor. Atmos. Phys. 1990, 44, 281-292. [CrossRef]

17. Gong, D.Y.; Ho, C.H. Intra-seasonal variability of wintertime temperature over East Asia. Int. J. Climatol. 2004, 24, 131-144. [CrossRef]

18. Jiang, X.N.; Adames, N.F.; Kim, D.; Maloney, E.D.; Lin, H.; Kim, H.; Zhang, C.D.; Demott, C.A.; Klingaman, N.P. Fifty Years of Research on the Madden-Julian Oscillation: Recent Progress, Challenges, and Perspectives. J. Geophys. Res. Atmos. $2020,125$. [CrossRef]

19. Liu, Y.Y.; Hu, Z.Z.; Wu, R.G.; Jha, B.; Li, Q.P.; Chen, L.J.; Yan, J.H. Subseasonal prediction and predictability of summer rainfall over eastern China in BCC_AGCM2.2. Clim. Dyn. 2021, 1-13. [CrossRef]

20. Xiang, B.Q.; Sun, Y.Q.; Chen, J.H.; Johnson, N.C.; Jiang, X.N. Subseasonal Prediction of Land Cold Extremes in Boreal Wintertime. J. Geophys. Res. Atmos. 2020, 125. [CrossRef]

21. Cheung, H.H.N.; Zhou, W. Implications of Ural Blocking for East Asian Winter Climate in CMIP5 GCMs. Part I: Biases in the Historical Scenario. J. Clim. 2015, 28, 2203-2216. [CrossRef]

22. Bueh, C.; Shi, N.; Xie, Z.W. Large-scale circulation anomalies associated with persistent low temperature over southern China in January 2008. Atmos. Sci. Lett. 2011, 12, 273-280. [CrossRef]

23. Shi, N.; Bueh, C. A specific stratospheric precursory signal for the extensive and persistent extreme cold events in China. Chin. J. Atmos. Sci. 2015, 39, 210-220. (In Chinese) [CrossRef]

24. Ji, L.R.; Sun, S.Q.; Arpe, K.; Bengtsson, L. Model study on the interannual variability of Asian winter monsoon and its influence. Adv. Atmos. Sci. 1997, 14, 1-22. [CrossRef]

25. Wang, L.; Chen, W. The East Asian winter monsoon: Re-amplification in the mid-2000s. Chin. Sci. Bull. 2014, 59, 430-436. [CrossRef]

26. Huang, R.H.; Chen, J.L.; Wang, L.; Lin, Z.D. Characteristics, processes, and causes of the spatio-temporal variabilities of the East Asian monsoon system. Adv. Atmos. Sci. 2013, 29, 910-942. [CrossRef]

27. Kuang, X.Y.; Zhang, Y.C.; Huang, D.Q.; Huang, Y. Regionality of record-breaking low temperature events in China and its associated circulation. Clim. Dyn. 2016, 46, 1719-1731. [CrossRef]

28. Luo, X.; Zhang, Y.C. The Linkage between Upper-Level Jet Streams over East Asia and East Asian Winter Monsoon Variability. J. Clim. 2015, 28, 9013-9028. [CrossRef]

29. Zhang, Y.C.; Chen, J. Characterizing the Winter Concurrent Variation Patterns of the Subtropical and Polar-Front Jets over East Asia. J. Meteorol. Res. 2017, 31, 160-170. [CrossRef]

30. Xue, D.K.; Zhang, Y.C. Concurrent variations in the location and intensity of the Asian winter jet streams and the possible mechanism. Clim. Dyn. 2017, 49, 37-52. [CrossRef]

31. Ren, Z.H.; Zou, F.L.; Yu, Y.; Wang, G.A. Daily Value Dataset of China's Surface Climate Data. 7 May 2020. Available online: http:/ / data.cma.cn (accessed on 7 May 2020).

32. Kalnay, E.; Kanamitsu, M.; Kistler, R.; Collins, W.; Deaven, D.; Gandin, L.; Iredell, M.; Saha, S.; White, G.; Woollen, J.; et al. The NCEP/NCAR 40-Year Reanalysis Project. Bull. Am. Meteorol. Soc. 1996, 77, 437-471. [CrossRef]

33. Yan, Z.; Jones, P.D.; Davies, T.D.; Moberg, A.; Bergstrm, H.; Camuffo, D.; Cocheo, C.; Maugeri, M.; Demare, G.R.; Verhoeve, T. Trends of Extreme Temperatures in Europe and China Based on Daily Observations. Clim. Chang. 2002, 53, 355-392. [CrossRef]

34. Zhang, Z.J.; Qian, W.H. Identifying Regional Prolonged Low Temperature Events in China. Adv. Atmos. Sci. 2011, 28, 338-351. [CrossRef]

35. Shi, N.; Wang, X.Q.; Tian, P.Y. Interdecadal variations in persistent anomalous cold events over Asian mid-latitudes. Clim. Dyn. 2018, 52, 3729-3739. [CrossRef]

36. Jiang, X.N.; Waliser, D.E. Northward propagation of the subseasonal variability over the eastern Pacific warm pool. Geophys. Res. Lett. 2008, 35, 697-711. [CrossRef]

37. Li, J.Y.; Wen, M.; Wang, Z.Y.; Hu, Y. Relations between the quasi-biweekly oscillation over the East Asian monsoon region and the East Asian tropical monsoon depressions. Int. J. Climatol. 2020, 41. [CrossRef]

38. Wen, M.; Yang, S.; Higgins, W.; Zhang, R.H. Characteristics of the Dominant Modes of Atmospheric Quasi-Biweekly Oscillation over Tropical-Subtropical Americas. J. Clim. 2011, 24, 3956-3970. [CrossRef] 
39. Murakami, M. Large-Scale Aspects of Deep Convective Activity over the GATE Area. Mon. Weather Rev. 1979, 107, 994-1013. [CrossRef]

40. Shanks, J.L. Recursion filters for digital processing. Geophysics 1967, 32, 33-51. [CrossRef]

41. Bueh, C.; Fu, X.Y.; Xie, Z.W. Large-Scale Circulation Features Typical of Wintertime Extensive and Persistent Low Temperature Events in China. Atmos. Oceanic Sci. Lett. 2011, 4, 235-241. [CrossRef]

42. Wang, L.; Chen, W.; Zhou, W.; Huang, R.H. Interannual Variations of East Asian Trough Axis at 500 hPa and its Association with the East Asian Winter Monsoon Pathway. J. Clim. 2009, 22, 600-614. [CrossRef]

43. Fu, X.Y.; Bueh, C. Wintertime extensive and persistent low-temperature events of China and anomalous precipitation over southern China. Chin. J. Atmos. Sci. 2013, 37, 1247-1260. (In Chinese) [CrossRef]

44. Yu, W.Q.; Gao, Q.J. Analysis and Diagnosis of Low-Frequency Characteristics in a Low Temperature Event in Southern China in the Winter of 1996. Chin. J. Atmos. Sci. 2020, 44, 257-268. (In Chinese) [CrossRef] 